Descriptive, Correlational and Qualitative Studies

Pensar en Movimiento:

Revista de Ciencias del Ejercicio y la Salud

EISSN: $1659-4436$

Vol. 13, No. 2, pp. $1-16$

Closing on December 31, 2015

\title{
AGE AND GENDER DIFFERENCES IN FUNDAMENTAL MOTOR SKILLS (original version in English ${ }^{1}$ )
}

\author{
Judith Jiménez-Díaz, M.Sc. ${ }^{1(A, B, C, D, E)}$, Walter Salazar-Rojas, Ph.D. ${ }^{1(B, D, E)}$ y María Morera, \\ Ph.D.2(B,D,E) \\ judith.jimenezd@ucr.ac.cr \\ ${ }^{1}$ School of Physical Education and Sports, University of Costa Rica, San Jose, Costa Rica \\ ${ }^{2}$ School of Human Movement and Quality of Life, National University, Heredia, Costa Rica
Original submission: 04-03-2015 Resubmitted: 11-07-2015/19-08-2015
Accepted: 27-08-2015 Published: 28-10-2015
doi: http://dx.doi.org/10.15517/pensarmov.v\%vi\%i.18327

\begin{abstract}
This manuscript underwent a hybrid review. We thank Milena Hernández, Lic., for her Open Peer
Review, in addition to the conventional double blind review.
\end{abstract}

\begin{abstract}
Jiménez-Díaz, J., Salazar-Rojas, W., \& Morera, M. (2015). Age and gender differences in fundamental motor skills. Pensar en Movimiento: Revista de Ciencias del Ejercicio y la Salud, 13(2), 1-16. Fundamental motor skills are the basis for participation in more advanced lifetime activities. Whereas considerable research has been reported on motor behavior of children, much less is known about performance in later years, especially adulthood. Therefore, the aim of this study was to examine age and gender differences on fundamental motor skills (FMS) ability across three age groups: children $(M=9.37 \mathrm{yr}$., $S D$ $=1.26)$, adolescents $(M=14.80$ yr., $S D=2.04)$ and young-adults $(M=19.88$ yr., $S D=$ 2.72). Participants ( $n=114$ ) were assessed on five locomotor skills (run, gallop, slide, hop, and distance jump) and five object control skills (bounce, catch, overhand throw, strike and kick) using the Test for Fundamental Motor Skills, which is a process-oriented instrument. ANOVA results comparing gender and group revealed no significant interactions. Moreover, main effects for group were found for three individual skills: galloping adolescents and young-adults performed better than children $(p<.01)$-, throwing -children and adolescents performed better than young-adults $(p<.01)$-, and kicking -young-adults performed better than children and adolescents $(p<.05)-$. Also, we found main effects for
\end{abstract}

\footnotetext{
${ }^{1}$ Also available in Spanish in this same journal.
} 
gender for total FMS ability $(p<.01)$, locomotor subscale $(p<.05)$ and object control subscale $(p<.01)$, and for six individual motor skills: run $(p<.05)$, jump $(p<.05)$, throw $(p$ $<.01)$, kick $(p<.01)$, bounce $(p<.01)$ and strike $(p<.01)$; males outperformed females for all the skills. However, in view of total FMS ability, locomotor skills and object control skills results suggest similar performance across ages. Therefore, it is important to enhance fundamental motor skills at all ages, as an option to help individuals engage in physical activities.

Key words: Locomotion, object control, motor performance, adulthood, gender bias, aging.

Sedentary behavior rates are increasing worldwide, despite the fact that the benefits of being physically active are well known. The underlying mechanisms that cause physical inactivity are not well understood (Okely, Booth, \& Patterson, 2001; Stodden et al., 2008); however, it is believed that motor competence plays an important role in physical activity behavior (Stodden et al., 2008).

Fundamental motor skills (FMS) are needed for participating in sports, games, and lifelong physical activity (Logan, Robinson, Wilson, \& Lucas, 2012; Stodden et al., 2008). FMS are usually classified in locomotor skills and object control skills. Locomotor skills involve movements that implicate moving the body through space, such as running, jumping and galloping. Object control skills consist of projecting or receiving objects, such as throwing, catching, kicking and striking (Gabbard, 2012; Stodden \& Goodway, 2007).

When a person understands how to move at the most basic level, it is easier to participate in different physical activities (Carley, 2010; Stodden et al., 2008). Therefore, we agree that FMS ability is an important factor to succeed in complex skills, and it also motivates to participate in games, sports and recreational activities, leading to a more active life, which is needed to maintain an adequate health-related fitness ( $\underline{\text { Carley, 2010; }}$ Stodden, Langendorfer, \& Roberton, 2009; Valentini \& Rudisill, 2004). In contrast, a person with lower FMS ability, has more probability to be physically inactive, because the lack of skill affects negatively the intention to participate in games and sports with their peers, causing them not to improve health-related fitness levels (Carley, 2010; Okely et al., 2001).

Research findings suggest that FMS ability is positively related to physical activity level (Cohen, Morgan, Plotnikoff, Callister, \& Lubans, 2014; Okely et al., 2001; Spessato, Gabbard, \& Valentini, 2013; Wrotniak, Epstein, Dorn, Jones, \& Kondilis, 2006) and health-related physical fitness (Okely, Booth, \& Chey, 2004; Slotte, Sääkslahti, Metsämuuronen, \& Rintala, 2014; Southall, Okely, \& Steele, 2004). For example, Wrotniak et al. (2006) found that FMS ability in children was positively related with physical activity - 2 -

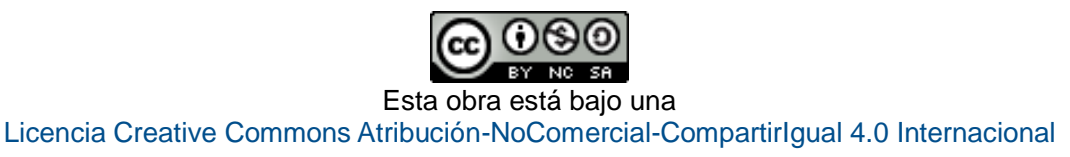


level. Likewise, Okely and colleagues (2001) concluded that participating in organized physical activities was related with FMS ability in adolescents. Moreover, $\underline{\text { Cohen et al. }}$ (2014) indicated that children with higher FMS ability spend more time in moderate to vigorous physical activities.

Regarding health-related physical fitness, Slotte et al. (2004) found that FMS ability was negatively related to body fat percentage in 8-years-olds. Similarly, Southall and colleagues (2004) reported an inverse relationship between FMS ability and body mass index (BMI) in children. Furthermore, Stodden et al. (2009) indicated a positive association between FMS ability and health-related physical fitness, including muscular strength and endurance and cardiorespiratory endurance; and also reported a negative association between FMS ability and body fat, in young-adults.

It has been hypothesized, by Seefeldt, that a minimal standard of FMS ability is needed to engage in a physical active lifestyle, which eventually will promote healthrelated physical fitness (Stodden et al., 2008). Considering that there is not enough data that indicates what the minimal standard is, we believe that it could be understood as a mature stage. This stage is characterized by a controlled performance and is commonly developed by the age of six or seven, and refined in the subsequent years (Gallahue \& Ozmun, 2005). Still, is important to recall that to perform at this level of proficiency and improve FMS ability, these skills must be learned, practiced and reinforced appropriately (Goodway \& Branta, 2003; Logan et al., 2012).

Despite the relevance that FMS proficiency had shown, as building blocks of movement, data indicated that FMS proficiency in childhood is low (Lubans, Morgan, Cliff, Barnett, \& Okely, 2010; Spessato, Gabbard, Valentini, \& Rudisill, 2012). Moreover; little is known about FMS proficiency after childhood (Barnett, van Beurden, Morgan, Brooks, \& Beard, 2010; Logan et al., 2012). Therefore, the purpose of this study was to examine age and gender differences in ten FMS abilities across three different age groups -children, adolescents, and young adults-. We hypothesized (a) that adolescents and young-adults would perform better than children and that (b) the male group would also perform better than the female group. 


\section{METHODS}

Participants. A total of 114 participants (See table 1), male $(n=59)$ and female $(n=55)$, aged between 8 and 27 years volunteered to participate in this study. The participants aged between 8 and 17 years, attended a community recreational summer program at one university in Costa Rica; while the participants aged between 18 and 27 years attended different Physical Education classes at the same university. All participants were healthy and did not present motor impairments. Written consent and assent were obtained from participants and/or guardians before the study.

Table 1

Participant Characteristics

\begin{tabular}{|c|c|c|c|c|}
\hline \multirow{2}{*}{ Group } & \multirow{2}{*}{ Characteristic } & \multicolumn{3}{|c|}{ Gender } \\
\hline & & Male & Female & Total \\
\hline \multirow{4}{*}{$\begin{array}{l}\text { Children } \\
\text { (8-11 years) }\end{array}$} & $\mathrm{N}$ & 22 & 16 & 38 \\
\hline & Age (yrs) & $9.64(1.29)$ & $9.00(1.15)$ & $9.37(1.26)$ \\
\hline & Weight $(\mathrm{kg})$ & $36.19(8.55)$ & $31.23(5.33)$ & $34.10(7.69)$ \\
\hline & Height $(\mathrm{cm})$ & $138.75(8.27)$ & $132.46(8.64)$ & $136.10(8.89)$ \\
\hline \multirow{4}{*}{$\begin{array}{l}\text { Adolescents } \\
\text { (12-17 years) }\end{array}$} & $\mathrm{N}$ & 18 & 17 & 35 \\
\hline & Age (yrs) & $14.33(2.09)$ & $15.29(1.93)$ & $14.80(2.04)$ \\
\hline & Weight $(\mathrm{kg})$ & $63.33(14.56)$ & $57.64(12.24)$ & $60.57(13.60)$ \\
\hline & Height $(\mathrm{cm})$ & $162.72(12.75)$ & $157.41(7.19)$ & $160.14(10.63)$ \\
\hline \multirow{4}{*}{$\begin{array}{l}\text { Young-adults } \\
\text { (18-27 years) }\end{array}$} & $\mathrm{N}$ & 19 & 22 & 41 \\
\hline & Age (yrs) & $19.42(1.98)$ & $20.27(3.22)$ & $19.88(2.72)$ \\
\hline & Weight $(\mathrm{kg})$ & $62.53(10.42)$ & $59.90(10.86)$ & $61.12(10.61)$ \\
\hline & Height $(\mathrm{cm})$ & $170.84(5.62)$ & $160.50(5.46)$ & $165.29(7.56)$ \\
\hline
\end{tabular}

Data shown as Mean (Standard Deviation)

Instruments. The Test for Fundamental Motor Skills (in Spanish Instrumento para la evaluación de Patrones Básicos de Movimiento -IPBM-) was used to measure the FMS ability in children, adolescents and adults (Jiménez, Salazar, \& Morera, 2013). This process-oriented test assesses 10 individual FMS arranged in two sub-scales: Locomotor (LM) skills (run, gallop, slide, distance jump and hop) and object control (OC) skills (catch, kick, strike, overhand throw and bounce). Reliability (intra-class coefficient $R=0.918$ ) and inter-rater reliability coefficient $(R=0.861)$ are adequate. The raw score for each individual skill, each subscale (locomotor and object control) and the total test (total FMS ability) range from 0 to 12 points. The total score for each subscale is an average of the five 
corresponding skills. Likewise, the total score for FMS ability is an average of the 10 individual motor skills. A score of 9 points or more indicates a proficiency level of the FMS. Height $(\mathrm{cm})$ was measured with a portable measuring board and a bioelectrical impedance scale (BF-682W TANITA) was used to measure body weight $(\mathrm{Kg})$. Height and weight were used for the descriptive characteristics of the sample.

Procedures. Following the institution research guides, all participants were measured for height and weight after signing the consent and filling out personal information. To establish the FMS ability, participants were videotaped performing the 10 FMS (run, jump, gallop, slide, hop, bounce, catch, kick, strike, and throw), in two trials. The assessment took place in a gymnasium, assessing one FMS at a time and one participant at a time. FMS ability was assessed from the videotape. As indicated in the test instructions, participants received 1 point for each present criterion or 0 points if not

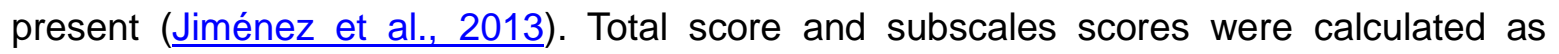
previously indicated.

Data Analysis. Data were analyzed for normal distribution ( $Q-Q$ Plots and Levene Test). Range, mean, standard deviation, and frequencies were calculated for descriptive proposes. A two-way ANOVA (Group [3] by Gender [2]) was used to examine differences of FMS ability (for the total score, subscales and individual skills). Tukey's test was used for

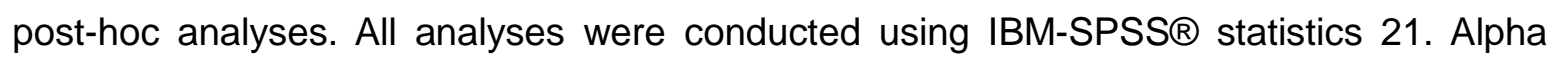
level for all analyses was set at 0.05 .

\section{RESULTS}

Residual plots and normal probability tests indicated that the data was normally distributed. Scores for the individual skills, subscales, and total FMS are shown in table 2. Proficiency level for the FMS ability total score was achieved by $36.8 \%$ of the children, $45.7 \%$ of the adolescents and $36.5 \%$ of the young-adults (See figure 1). Table 3 shows the percentage of proficiency level achieved for the individual skills, subscales and total score for FMS ability.

The ANOVA results showed no significant interaction for the total score, the LM and - 5 -

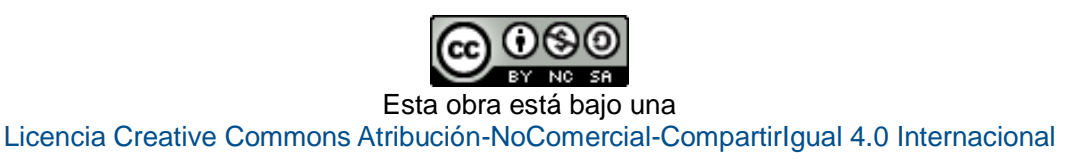


OC subscales, and any of the individual skills. Main effects were found for age groups and gender. The results for the ANOVA are shown in table 4.

\section{Age group differences}

No differences were found for the total score and for both of the subscales (See figure 2), indicating that all groups had similar performance. For the individual skills, group differences were found in gallop (young-adults and adolescents had better performance than children), throw (young-adults presented a lower performance than children and adolescents) and kick (young-adults performed better than children and adolescents) (see figure 3).

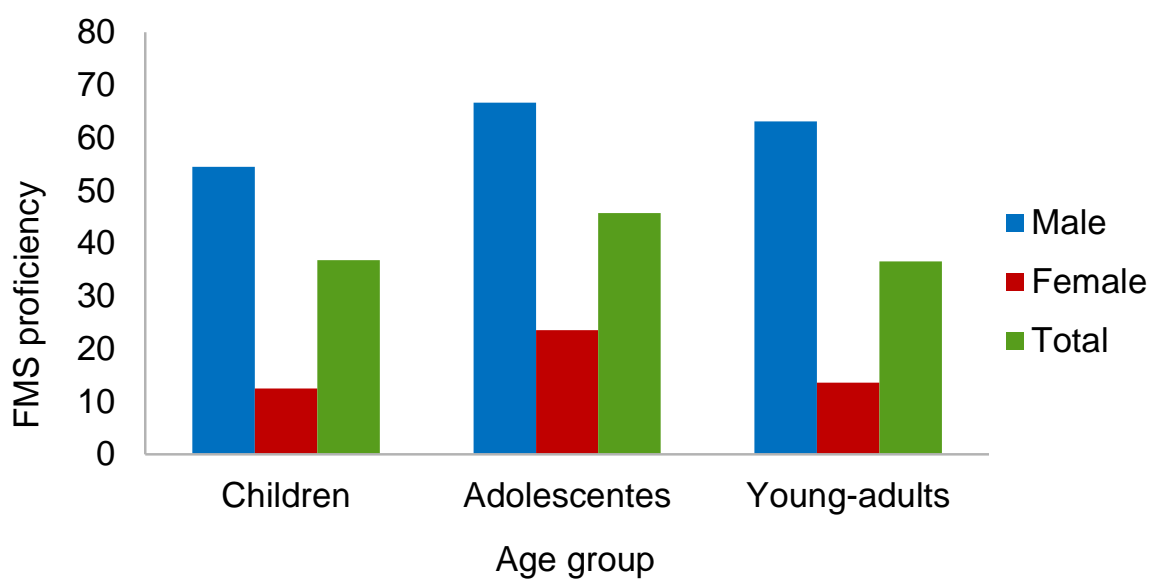

Figure 1. Percentage of the participants that achieved proficiency level in the Fundamental Motor Skills ability

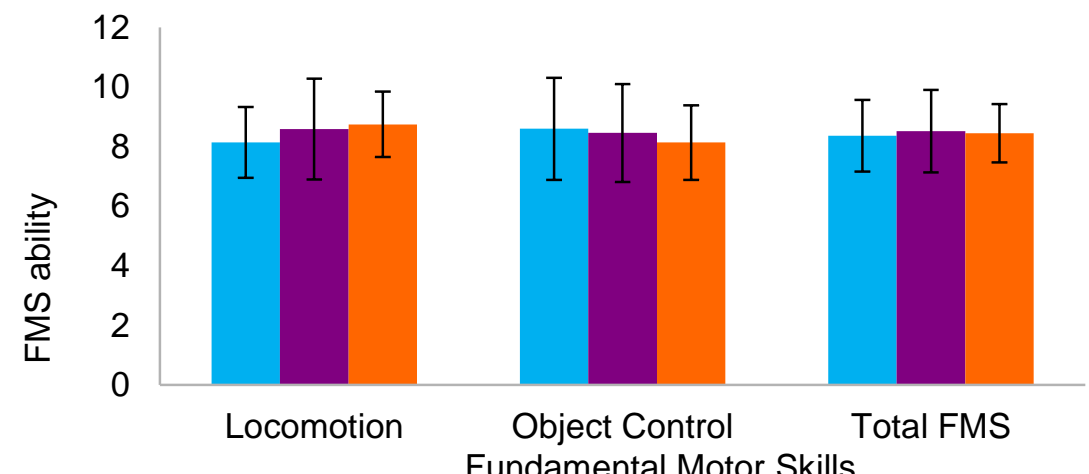

- Children Adolescents Young-adults

Figure 2. Fundamental Motor Skills ability of the total FMS, locomotor and object control subscales, by age group. 
Table 2

Participant descriptive data for FMS ability

\begin{tabular}{|c|c|c|c|c|c|c|c|c|c|}
\hline \multirow{2}{*}{ FMS } & \multicolumn{3}{|c|}{ Children } & \multicolumn{3}{|c|}{ Adolescents } & \multicolumn{3}{|c|}{ Young-adults } \\
\hline & Male & Female & Total & Male & Female & Total & Male & Female & Total \\
\hline Run & $9.00(1.8)$ & $8.69(1.2)$ & $8.87(1.6)$ & $9.06(1.8)$ & $8.12(1.4)$ & $8.60(1.6)$ & $9.37(1.3)$ & $8.64(1.8)$ & $8.98(1.6)$ \\
\hline Gallop & $7.86(2.6)$ & $6.94(3.8)$ & $7.47(3.1)$ & $8.94(2.9)$ & $8.29(2.2)$ & $8.63(2.5)$ & $10.05(1.6)$ & $8.86(1.5)$ & $9.41(1.6)$ \\
\hline Hop & $9.00(1.9)$ & $8.25(1.9)$ & $8.68(1.9)$ & $8.72(2.8)$ & $8.29(1.7)$ & $8.51(2.3)$ & $8.79(2.3)$ & $8.64(1.8)$ & $8.71(2.0)$ \\
\hline Jump & $7.41(2.9)$ & $7.06(2.9)$ & $7.26(2.9)$ & $9.44(2.6)$ & $7.59(2.8)$ & $8.54(2.8)$ & $9.32(2.5)$ & $7.82(2.6)$ & $8.51(2.6)$ \\
\hline Slide & $8.27(2.4)$ & $8.56(2.5)$ & $8.39(2.4)$ & $8.33(2.6)$ & $9.00(1.4)$ & $8.66(2.1)$ & $8.26(2.1)$ & 8.05() 2.5 & $8.15(2.3)$ \\
\hline Bounce & $7.68(1.8)$ & $6.63(2.4)$ & $7.24(2.1)$ & $8.44(1.7)$ & $6.82(2.5)$ & $7.66(2.2)$ & $8.84(1.5)$ & $7.18(1.5)$ & $7.95(1.7)$ \\
\hline Throw & $8.55(3.1)$ & $6.50(3.5)$ & $7.68(3.4)$ & $9.11(2.1)$ & $6.65(4.0)$ & 7.91(3.4) & $5.26(2.6)$ & $4.64(3.0)$ & $4.93(2.8)$ \\
\hline Catch & $9.50(2.1)$ & $9.94(1.8)$ & $9.68(1.9)$ & $9.06(1.7)$ & $8.94(1.8)$ & $9.00(1.7)$ & $9.21(1.7)$ & $8.82(1.9)$ & $9.00(1.8)$ \\
\hline Kick & $10.73(2.1)$ & $7.50(2.3)$ & $9.37(2.7)$ & $10.28(2.6)$ & $8.41(2.4)$ & $9.37(2.6)$ & $11.47(0.8)$ & $9.23(1.6)$ & $10.27(1.7)$ \\
\hline Strike & $9.55(2.2)$ & $8.31(2.4)$ & $9.03(2.3)$ & $9.06(1.5)$ & $7.59(1.9)$ & $8.34(1.9)$ & $9.89(1.7)$ & $7.41(2.4)$ & $8.56(2.4)$ \\
\hline $\begin{array}{l}\text { Locomotion } \\
\text { subscale }\end{array}$ & $8.31(1.2)$ & $7.90(1.2)$ & $8.14(1.2)$ & $8.90(2.1)$ & $8.26(1.0)$ & $8.59(1.7)$ & $9.16(1.0)$ & $8.40(1.1)$ & $8.75(1.1)$ \\
\hline $\begin{array}{l}\text { Object } \\
\text { Control } \\
\text { subscale }\end{array}$ & $9.20(1.7)$ & $7.78(1.4)$ & $8.60(1.7)$ & $9.19(1.1)$ & $7.68(1.8)$ & $8.46(1.6)$ & $8.94(0.9)$ & $7.45(1.1)$ & $8.14(1.3)$ \\
\hline Total FMS & $8.75(1.2)$ & $7.84(0.9)$ & $8.37(1.2)$ & $9.04(1.4)$ & 7.97(1.2) & $8.52(1.4)$ & $9.05(0.6)$ & $7.93(0.9)$ & $8.45(1.0)$ \\
\hline
\end{tabular}

Data shown as Mean (Standard Deviation) 
Table 3

Percentage of participants that achieved proficiency level

\begin{tabular}{|c|c|c|c|c|c|c|c|c|c|}
\hline \multirow{2}{*}{ FMS } & \multicolumn{3}{|c|}{$\underline{\text { Children }}$} & \multicolumn{3}{|c|}{ Adolescents } & \multicolumn{3}{|c|}{ Young-adults } \\
\hline & Male & Female & Total & Male & Female & Total & Male & Female & Total \\
\hline$\overline{R u n}$ & 59.1 & 56.3 & 57.9 & 61.1 & 35.3 & 48.6 & 73.7 & 59.1 & 65.9 \\
\hline Gallop & 45.5 & 37.5 & 42.1 & 66.7 & 64.7 & 65.7 & 89.5 & 59.1 & 73.2 \\
\hline Hop & 63.6 & 37.5 & 52.6 & 61.1 & 52.9 & 57.1 & 63.2 & 54.5 & 58.5 \\
\hline Jump & 40.9 & 37.5 & 39.5 & 61.1 & 41.2 & 51.4 & 68.4 & 40.9 & 53.7 \\
\hline Slide & 40.9 & 62.5 & 50.0 & 55.6 & 70.6 & 62.9 & 36.8 & 40.9 & 39.0 \\
\hline Bounce & 27.3 & 12.5 & 21.1 & 44.4 & 23.5 & 34.3 & 42.1 & 13.6 & 26.8 \\
\hline Throw & 54.5 & 25.0 & 42.1 & 50.0 & 47.1 & 48.6 & 15.8 & 18.2 & 17.1 \\
\hline Catch & 77.3 & 75.0 & 76.3 & 61.1 & 64.7 & 62.9 & 63.2 & 54.5 & 58.5 \\
\hline Kick & 86.4 & 37.5 & 65.8 & 83.3 & 47.1 & 65.7 & 100.0 & 68.2 & 82.9 \\
\hline Strike & 77.3 & 56.3 & 68.4 & 61.1 & 35.3 & 48.6 & 78.9 & 40.9 & 58.5 \\
\hline $\begin{array}{l}\text { Locomotion } \\
\text { subscale }\end{array}$ & 31.8 & 18.8 & 26.3 & 72.2 & 17.6 & 45.7 & 52.6 & 22.7 & 36.6 \\
\hline $\begin{array}{l}\text { Object Control } \\
\text { subscale }\end{array}$ & 63.6 & 25.0 & 47.4 & 61.1 & 35.3 & 48.6 & 42.1 & 4.5 & 22.0 \\
\hline Total FMS & 54.5 & 12.5 & 36.8 & 66.7 & 23.5 & 45.7 & 63.2 & 13.6 & 36.6 \\
\hline
\end{tabular}

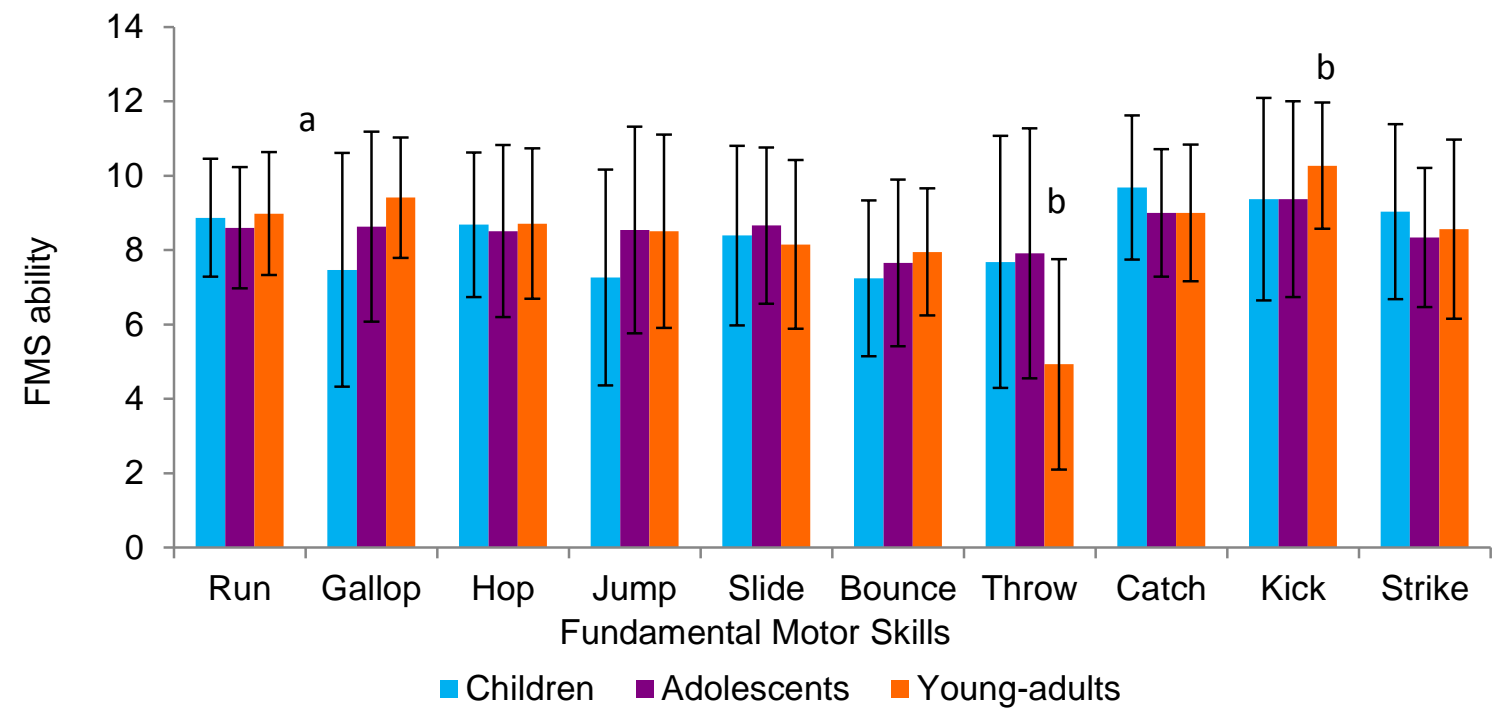

Figure 3. Fundamental Motor Skills ability of the individual fundamental motor skills, by age group. ${ }^{a}$ Children different from adolescents and young-adults in gallop. ${ }^{b}$ Young-adults different from children and adolescents in throw and kick ( $p<.05)$. 
Table 4

ANOVA $F$ values for main effects and interaction

\begin{tabular}{lcccccc}
\hline & \multicolumn{2}{c}{ Group } & \multicolumn{2}{c}{ Gender } & \multicolumn{2}{c}{ Group by Gender } \\
\cline { 2 - 7 } \multicolumn{1}{c}{ FMS } & $F$ & $p$ & $F$ & $p$ & $F$ & $p$ \\
\hline Run & .634 & .533 & $4.737^{*}$ & .032 & .357 & .701 \\
Gallop & $6.687^{\star}$ & .002 & 3.862 & .052 & .111 & .895 \\
Hop & .089 & .915 & 1.243 & .267 & .194 & .824 \\
Jump & 2.904 & .059 & $5.826^{*}$ & .017 & .776 & .463 \\
Slide & .472 & .625 & .324 & .570 & .356 & .701 \\
Bounce & 1.978 & .143 & $16.212^{*}$ & .001 & .295 & .745 \\
Throw & $10.354^{*}$ & .001 & $8.584^{*}$ & .004 & .934 & .396 \\
Catch & 1.827 & .166 & .004 & .948 & .496 & .610 \\
Kick & $4.079^{*}$ & .020 & $40.468^{*}$ & .001 & 1.083 & .342 \\
Strike & .774 & .464 & $19.576^{*}$ & .001 & 1.013 & .366 \\
Locomotion subscale & 2.63 & .076 & $5.86^{*}$ & .017 & .174 & .841 \\
Object Control subscale & .503 & .606 & $32.21^{*}$ & .001 & .008 & .992 \\
Total FMS & .428 & .653 & $25.641^{*}$ & .001 & .091 & .913 \\
\hline
\end{tabular}

${ }^{{ }^{*} p<.05}$

\section{Gender differences}

Gender differences were found for the total score and for both subscales indicating that men had better performance than women (See figure 4). For the individual skills gender differences were found in run, jump, bounce, throw, kick and strike, males outperformed the females (see figure 5). 


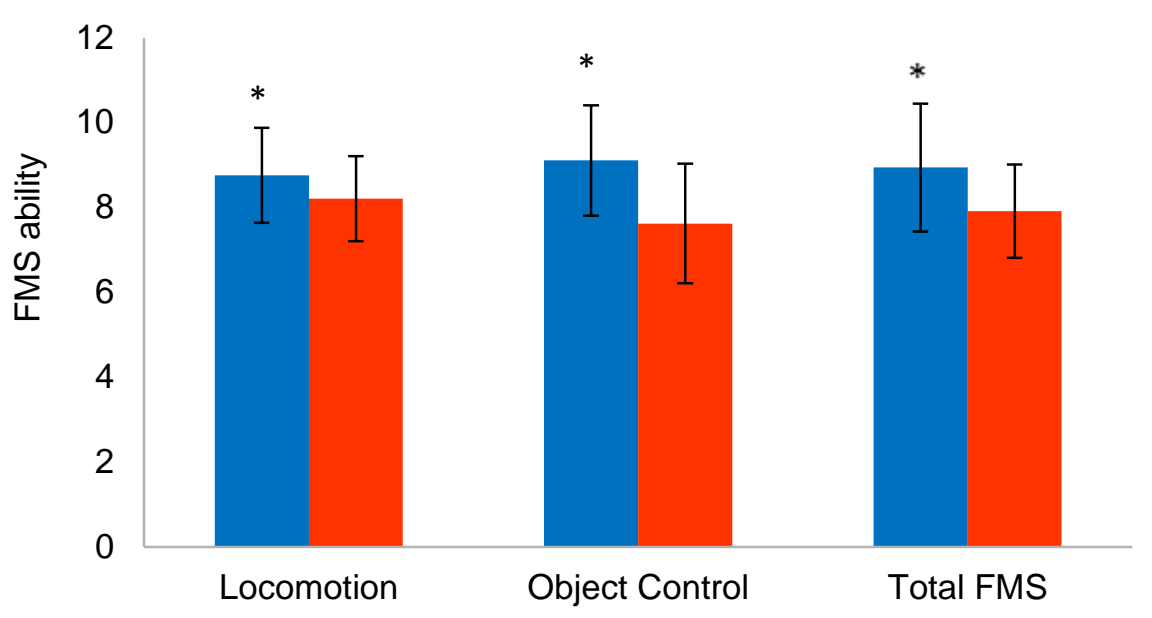

Fundamental Motor Skills

- Male $\quad$ Female

Figure 4. Fundamental Motor Skills ability of the total FMS, locomotor and object control subscales, by gender. ${ }^{*}$ Male different from female $(p<.05)$

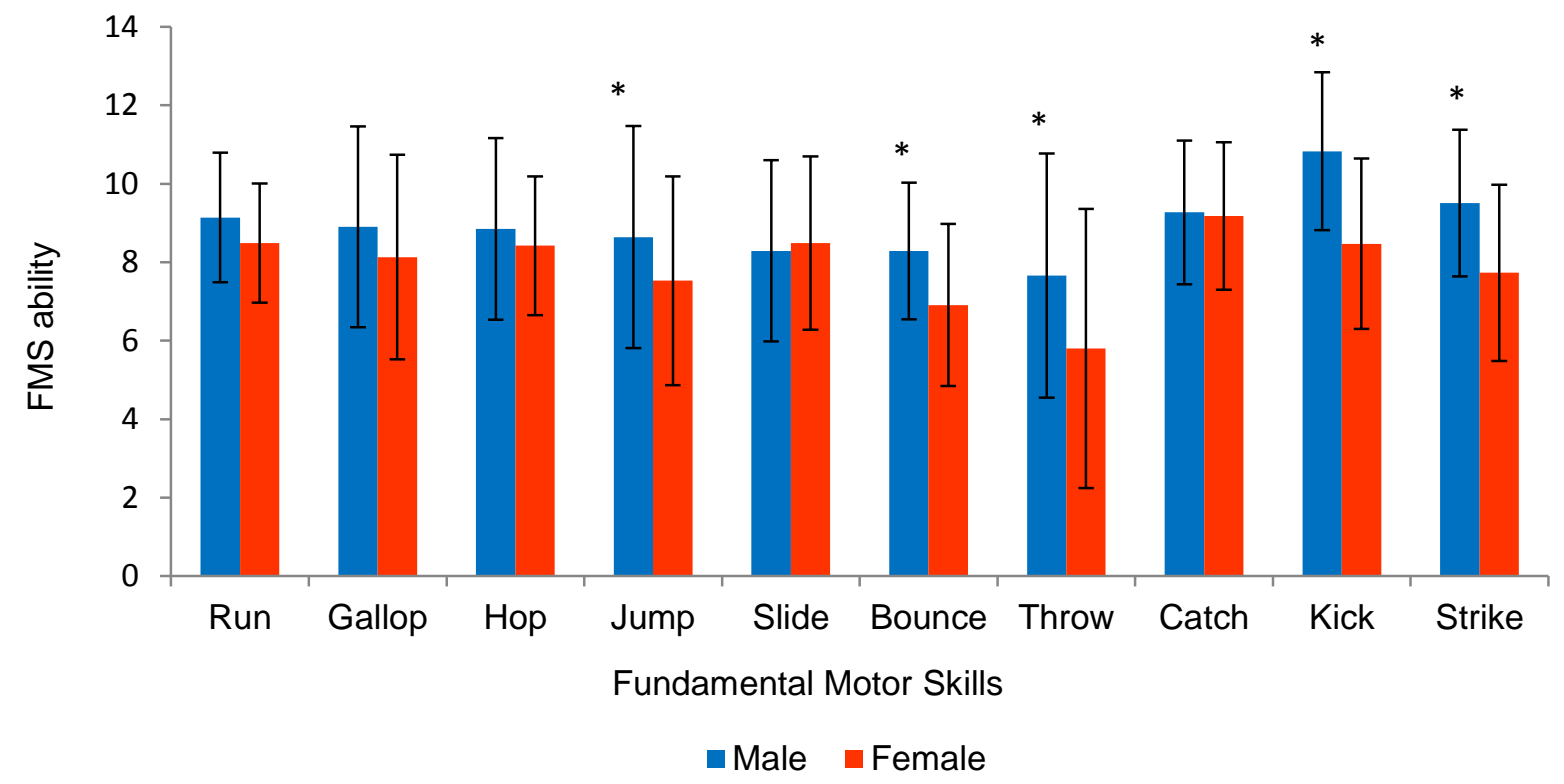

Figure 5. Fundamental Motor Skills ability of the individual fundamental motor skills, by gender. ${ }^{*}$ Male different from female $(p<.05)$ 


\section{DISCUSSION}

The purpose of this study was to examine age and gender differences in FMS ability of three different age groups. We expected a better performance in adolescents and young-adults compared to children, however, the results did not support our hypothesis for the total FMS ability and both subscales (LM and OC). According to our second hypothesis, we found that the male group performed better than the female group for the total FMS ability and both subscales (LM and OC).

In general, most of the participants did not achieve a FMS proficiency level; this is represented by a score of 9 points or less. The adolescent male group exhibited the highest percentage of achievement while the children and young-adult female group showed the lowest percentage. Due to these results and the relationship between physical activity and motor competence, we believe that this level of performance may contribute to a sedentary behavior.

For our first hypothesis, we expected a higher performance of the adolescents and young-adults compared to the children. When assessing the total FMS ability and by subscales, our results suggest that the performance across all age group is similar and under a FMS proficiency level. Therefore, we speculate that most of the participants are not practicing and refining the fundamental motor skills in an appropriate learning environment, or even worse, they are not practicing these skills at all.

When analyzed by individual skills, adolescents and young-adults outperformed children in galloping, and also only in this skill did the young-adults achieve a proficiency level. A similar trend was found by Barnett et al. (2010) and Hardy et al. (2012) when assessing locomotor skills in children and adolescents. In addition, we found that in kicking all age groups achieved a proficiency level and young-adults had a better performance than children and adolescents. In contrast, Barnett and colleagues (2010) found that kicking had a low percentage of improvement from childhood to adolescence, compared to other skills like catch and throw. This is not surprising considering that in Costa Rica soccer, which involves kicking, is the most popular sport. Although, is important to consider that Barnett et al. research was based on a longitudinal sample, while our results are based on a cross-sectional sample. 
Also, another skill that exhibited age group differences was over-arm throwing, as we found that young-adults showed a lower performance than children and adolescents. Similar results were found by Hardy et al. (2012) when assessing catch, kick, and overarm throw in children and adolescents. Contrary to our results, Lorson et al. (2013) found that young-adult had a better performance than adolescents. A possible explanation for our findings is that children and adolescents today have more opportunities than the youngadults when they were children or adolescents, therefore they exhibit a higher ability. Other possible explanation is that after adolescence, young-adults stop practicing activities that include over-arm throw, therefore there could be a decrease in the performance due to lack of practice.

These results support our second hypothesis, gender differences found in the total FMS, both subscales and in five of the individual FMS assessed are consistent with other studies (Barnett et al., 2010; Hardy et al., 2012; Lorson et al., 2013; Spessato et al., 2012; Thomas \& French, 1985). The male group outperformed the female group in running, jumping, kicking, striking, and over-arm throwing. Similar to these findings Lorson and colleagues (2013) found that men and boys outperformed girls and women in the over-arm throw. Also, Barnett et al. (2010) confirm that boys had better performance than girls particularly in object control skills. A possible explanation for the gender differences is that when performance is assessed using process-oriented rather than product-oriented instruments, gender differences are likely to be attributable to social factors instead of biological factors (Hardy et al., 2012).

It is known that FMS ability is not age-dependent and does not develop naturally. Also, the task, the individual, and the environment have an important role in the performance of motor skills (Gallahue \& Ozmun, 2005; Valentini \& Rudisill, 2004). Furthermore, proficiency level can be achieved with adequate practice, instruction and learning opportunities (Logan et al., 2012; Lubans et al., 2010; Valentini \& Rudisill, 2004). Consequently, a possible explanation of these findings is that children, adolescents, and young-adults are not receiving adequate practice, instructions, or learning opportunities to improve their FMS ability. Due to these results, it is very important for Physical Education (PE) teachers to incorporate FMS practice, as proposed by Carley (2010).

Considering that FMS ability is positively related to physical activity level and physical fitness, and also presents a negative relationship with body mass index (Okely et -12 -

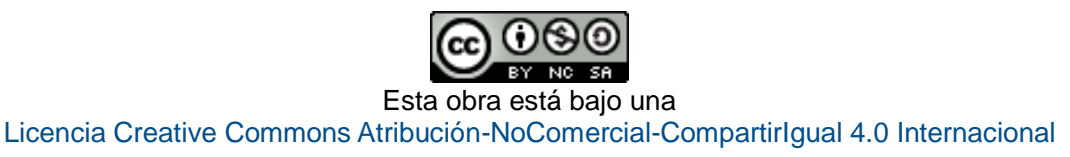


al., 2004, 2001; Stodden et al., 2009; Stodden, True, Langendorfer, \& Gao, 2013); we speculate that if FMS ability is improved, physical activity level and physical fitness may increase, and body mass index may decrease. Motor skills interventions are effective strategies for improving FMS performance in children (Logan et al., 2012), but little is known about whether these strategies are also effective in adolescents and young adults. Hence, it is necessary to develop interventions that help not only children but adolescents and young-adults as well, to reach a proficiency level in FMS.

We support the idea that individuals engage in an active lifestyle through the implementation of FMS in games, recreational activities and sports (Lubans et al., 2010; Robinson, 2011). Based on our results, and considering the limitation of a cross-sectional study, we believe that low FMS ability shown across different age groups may be one of many factors that may explain the increased rate of sedentary behavior. Therefore, we agree that FMS ability plays an important role in an individual's choice to be physically active. Also, we think it plausible that low levels of physical activity, especially in early childhood, do not encourage enough practice to rich FMS proficiency levels, as suggested in Stodden, et al. (2008).

When assessing FMS ability by process, gender differences are attributed to social factors: we encourage PE teachers, couches and health professionals, not to underestimate girls and women just because of their gender, but to try to encourage them to practice all FMS and to keep physically active. Also, due to the results, we also encourage all health professionals to take their time and teach FMS to all age groups, and to not assume that just because they are not children, they perform FMS proficiently.

\section{CONCLUSIONS}

In conclusion, the similar performance we found across ages in most FMS suggests that adolescents and young-adults are not improving their performance in the basics skills and are not achieving a proficiency level. Due to the relevance of FMS in physical activity levels and in health-related fitness, it is important for PE teachers, professionals related to human movement sciences and teachers in charge of physical activity classes to include activities to strengthen FMS at all ages, and to help the students achieve mastery proficiency. 


\section{REFERENCES}

Barnett, L. M., van Beurden, E., Morgan, P. J., Brooks, L. O., \& Beard, J. R. (2010). Gender differences in motor skill proficiency from childhood to adolescence: A longitudinal study. Research Quarterly for Exercise and Sport, 81(2), 162-170. Retrieved from http://www.tandfonline.com/doi/abs/10.1080/02701367.2010.10599663

Carley, M. (2010). The relationship between fundamental motor skill development and lifetime participation in physical activity. PSAHPERD, winter, 31-33.

Cohen, K. E., Morgan, P. J., Plotnikoff, R. C., Callister, R., \& Lubans, D. R. (2014). Fundamental movement skills and physical activity among children living in lowincome communities: a cross-sectional study. International Journal of Behavioral Nutrition and Physical Activity, 11(1), 49-58. http://dx.doi.org/10.1186/1479-5868-11-49

Gabbard, C. P. (2012). Lifelong Motor Development (6th ed.). San Francisco: BenjaminCummings Publishing Company. Retrieved from http://www.pearsonhighered.com/bookseller/product/Lifelong-MotorDevelopment/9780321734945.page

Gallahue, D. L., \& Ozmun, J. C. (2005). Understanding Motor Development: Infants, Children, Adolescents, Adults (6th ed.). McGraw-Hill Higher Education. Retrieved from http://trove.nla.gov.au/work/11623306

Goodway, J. D., \& Branta, C. F. (2003). Influence of a motor skill intervention on fundamental motor skill development of disadvantaged preschool children. Research Quarterly for Exercise and Sport, 74(1), 36-46. http://dx.doi.org/10.1080/02701367.2003.10609062

Hardy, L. L., Reinten-Reynolds, T., Espinel, P., Zask, A., \& Okely, A. D. (2012). Prevalence and correlates of low fundamental movement skill competency in children. Pediatrics, 130(2), e390-e398. http://dx.doi.org/10.1542/peds.2012-0345

Jiménez, J., Salazar, W., \& Morera, M. (2013). Diseño y validación de un instrumento para la evaluación de patrones básicos de movimiento. Motricidad. European Journal of Human Movement, 31(0), 87-97. Retrieved from http://www.eurihm.com/index.php/eurihm/article/view/311

Logan, S. W., Robinson, L. E., Wilson, A. E., \& Lucas, W. A. (2012). Getting the fundamentals of movement: A meta-analysis of the effectiveness of motor skill interventions in children. Child: Care, Health and Development, 38(3), 305-315. 
http://dx.doi.org/10.1111/j.1365-2214.2011.01307.x

Lorson, K. M., Stodden, D. F., Langendorfer, S. J., \& Goodway, J. D. (2013). Age and gender differences in adolescent and adult overarm throwing. Research Quarterly for Exercise and Sport, 84(2), 239-244. http://dx.doi.org/10.1080/02701367.2013.784841

Lubans, D. R., Morgan, P. J., Cliff, D. P., Barnett, L. M., \& Okely, A. D. (2010). Fundamental movement skills in children and adolescents. Sports Medicine, 40(12), 1019-1035. http://dx.doi.org/10.2165/11536850-000000000-00000

Okely, A. D., Booth, M. L., \& Chey, T. (2004). Relationships between body composition and fundamental movement skills among children and adolescents. Research Quarterly for $\begin{array}{llll}\text { Exercise } \quad \text { Sport, } & \text { 238-247. }\end{array}$ http://dx.doi.org/10.1080/02701367.2004.10609157

Okely, A. D., Booth, M. L., \& Patterson, J. W. (2001). Relationship of physical activity to fundamental movement skills among adolescents. Medicine and Science in Sports and Exercise, 33(11), 1899-1904. http://dx.doi.org/10.1097/00005768-200111000-00015

Robinson, L. E. (2011). The relationship between perceived physical competence and fundamental motor skills in preschool children. Child: Care, Health and Development, 37(4), 589-596. http://dx.doi.org/10.1111/j.1365-2214.2010.01187.x

Slotte, S., Sääkslahti, A., Metsämuuronen, J., \& Rintala, P. (2014). Fundamental movement skill proficiency and body composition measured by dual energy X-ray absorptiometry in eight-year-old children. Early Child Development and Care, 1-11. http://dx.doi.org/10.1080/03004430.2014.936428

Southall, J., Okely, A. D., \& Steele, J. (2004). Actual and perceived physical competence in overweight and nonoverweight children. Pediatric Exercise Science, 16(1), 15-24. Retrieved from http://journals.humankinetics.com/pes-backissues/PESVolume16lssue1February/ActualandPerceivedPhysicalCompetenceinOver weightandNonoverweightChildren

Spessato, B., Gabbard, C., \& Valentini, N. C. (2013). The role of motor competence and body mass index in children's activity levels in physical education classes. Journal of Teaching in Physical Education, 32(2), 118-130. Retrieved from http://journals.humankinetics.com/itpe-back-issues/itpe-volume-32-issue-2-april/therole-of-motor-competence-and-body-mass-index-in-childrenrsquos-activity-levels-inphysical-education-classes

Spessato, B., Gabbard, C., Valentini, N., \& Rudisill, M. (2012). Gender differences in Brazilian $-15-$

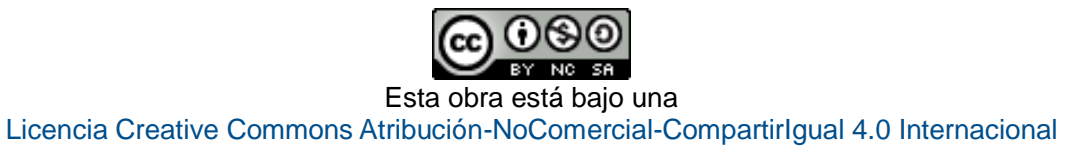


children's fundamental movement skill performance. Early Child Development and Care, 183(7), 916-923. http://dx.doi.org/10.1080/03004430.2012.689761

Stodden, D. F., \& Goodway, J. D. (2007). The dynamic association between motor skill development and physical activity. Journal of Physical Education, Recreation \& Dance, 78(8), 33-49. http://dx.doi.org/10.1080/07303084.2007.10598077

Stodden, D. F., Goodway, J. D., Langendorfer, S. J., Roberton, M. A., Rudisill, M. E., Garcia, C., \& Garcia, L. E. (2008). A developmental perspective on the role of motor skill competence in physical activity: An emergent relationship. Quest, 60(2), 290-306. http://dx.doi.org/10.1080/00336297.2008.10483582

Stodden, D. F., Langendorfer, S., \& Roberton, M. A. (2009). The association between motor skill competence and physical fitness in young adults. Research Quarterly for Exercise and Sport, 80(2), 223-229. http://dx.doi.org/10.1080/02701367.2009.10599556

Stodden, D. F., True, L. K., Langendorfer, S. J., \& Gao, Z. (2013). Associations among selected motor skills and health-related fitness: indirect evidence for Seefeldt's proficiency barrier in young adults? Research Quarterly for Exercise and Sport, 84(3), 397-403. http://dx.doi.org/10.1080/02701367.2013.814910

Valentini, N., \& Rudisill, M. E. (2004). Motivational climate, motor-skill development, and perceived competence: Two studies of developmentally delayed kindergarten children. Journal of Teaching in Physical Education, 23(3), 216-234. Retrieved from http://journals. humankinetics.com/itpe-back-

issues/JTPEVolume23Issue3July/MotivationalClimateMotorSkillDevelopmentandPerce ivedCompetenceTwoStudiesofDevelopmentallyDelayedKindergartenChildren

Wrotniak, B. H., Epstein, L. H., Dorn, J. M., Jones, K. E., \& Kondilis, V. A. (2006). The relationship between motor proficiency and physical activity in children. Pediatrics, 118(6), e1758-e1765. http://dx.doi.org/10.1542/peds.2006-0742

Contribution: A- Funding, B- Study design, C- Data collection, D- Statistical analysis and interpretation of results, E- Manuscript preparation. 